\title{
Outcomes of mitral valve replacement in children: A competing-risks analysis
}

\author{
Fatemeh Kojori ${ }^{\mathrm{a}}$ \\ Rui Chen, MD ${ }^{\mathrm{a}, \mathrm{b}}$ \\ Christopher A. Caldarone, $\mathrm{MD}^{\mathrm{b}}$ \\ Sandra L. Merklinger, $\mathrm{PhD}^{\mathrm{a}}$ \\ Anthony Azakie, MD ${ }^{\mathrm{b}}$ \\ William G. Williams, MD ${ }^{b}$ \\ Glen S. Van Arsdell, MD ${ }^{\mathrm{b}}$ \\ John Coles, MD ${ }^{\mathrm{b}}$ \\ Brian W. McCrindle, MD, MPH ${ }^{\mathrm{a}}$
}

From the Division of Cardiology, Department of Pediatrics, ${ }^{a}$ and Division of Cardiovascular Surgery, Department of Surgery, ${ }^{b}$ The Hospital for Sick Children, University of Toronto, Toronto, Ontario, Canada.

Read at the Eighty-fourth Annual Meeting of The American Association for Thoracic Surgery, Toronto, Ontario, Canada, April 25-28, 2004.

Received for publication April 23, 2004; revisions received July 24, 2004; accepted for publication July 26, 2004.

Address for reprints: Brian McCrindle, MD, The Hospital for Sick Children, 555 University Ave, Toronto, Ontario, Canada M5G 1X8 (E-mail: brian.mccrindle@sickkids.ca).

J Thorac Cardiovasc Surg 2004;128:703-9

$0022-5223 / \$ 30.00$

Copyright (c) 2004 by The American Association for Thoracic Surgery

doi:10.1016/j.jtcvs.2004.07.024
Objective: We sought to define patient characteristics, outcomes, and associated factors after mitral valve replacement in children.

Methods: We included 104 children undergoing at least one mitral valve replacement between 1980 and 2003 and reviewed clinical records. Competing-risks methodology was used to determine time-related prevalence and associated risk factors after initial mitral valve replacement for death and repeat replacement.

Results: The underlying mitral valve disease was congenital in $83 \%$, rheumatic in $13 \%$, Marfan syndrome in 3\%, and isolated endocarditis in 1\%, with $64 \%$ having primarily regurgitation, $16 \%$ having stenosis, $20 \%$ having both, and $32 \%$ having undergone previous valvotomy, valvuloplasty, or repair. There were 137 valve replacements, with 26 patients having more than one. Valve prosthesis type was $\mathrm{St}$ Jude Medical in 37\%, Björk-Shiley in 25\%, Carbomedics in 20\%, Ionescu-Shiley in $10 \%$, and other types in $8 \%$. Both early and late complications were common. Median age at the initial replacement was 5.9 years (range, birth to 19 years). Competing-risks analysis predicted $19 \%$ to have died at 15 years after initial replacement, with risk factors including noncongenital valve morphology, lower weight, and longer duration of cardiopulmonary bypass. A repeat replacement was predicted for $71 \%$, with risk factors including the presence of multiple left-heart obstructive lesions and Ionescu-Shiley valve prosthesis.

Conclusions: Mitral valve replacement might be necessary in children with extremely dysplastic valves and severe hemodynamic impairment or after failed repair. However, with the appropriate selection of the prosthetic valve and reduction of cardiopulmonary bypass time, surgeons might decrease mortality and increase prosthesis longevity.

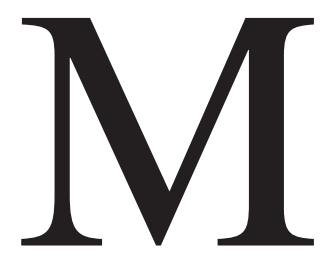

itral valve replacement (MVR) or systemic atrioventricular valve replacement is associated with unique clinical and technical difficulties in pediatric patients. Outcomes of MVR are well documented, ${ }^{1-4}$ and a strong incentive exists to repair rather than replace the valve when possible. Patients undergoing MVR within the first few years of life pose several challenges, including the small size of the valve annulus, left atrium, and left ventricle in relation to available prostheses, with subsequent potential for leaflet entrapment, left ventricular outflow tract obstruction, and conduction block. ${ }^{4-6}$ Late 
TABLE 1. Procedural characteristics at initial, and subsequent MVRs combined $(n=137)$

\begin{tabular}{lccc}
\hline Variable & N & Missing & Value \\
\hline $\begin{array}{l}\text { Age at MVR, y } \\
\text { (median and range) }\end{array}$ & 137 & 0 & 7.4 (birth to 19) \\
$\begin{array}{l}\text { Weight at MVR, kg } \\
\text { (median and range) }\end{array}$ & 125 & 12 & $20(2.8-73)$ \\
$\begin{array}{l}\text { Duration of cardiopulmonary } \\
\quad \text { bypass, min }\end{array}$ & 119 & 18 & $154 \pm 75$ \\
$\begin{array}{l}\text { Duration of aortic } \\
\quad \text { rossclamping, min }\end{array}$ & 110 & 27 & $97 \pm 50$ \\
$\begin{array}{l}\text { Type of MV replacement } \\
\text { St Jude Medical }\end{array}$ & 137 & 0 & \\
$\quad$ Björk-Shiley & & & $50(37 \%)$ \\
$\quad$ Carbomedics & & & $34(25 \%)$ \\
$\quad$ lonescu-Shiley & & & $27(20 \%)$ \\
$\quad$ Hancock & & & $6(10 \%)$ \\
$\quad$ Homograft & & & $3(2 \%)$ \\
$\quad$ Carpentier-Edwards & & & $2(1 \%)$ \\
$\quad$ Fascia lata & $1(<1 \%)$ \\
Size of MV implant, mm & 136 & 1 & $24 \pm 5$ \\
Size of implant per kg body & 124 & 13 & $1.2(0.4-6.4)$ \\
$\quad$ weight, mm/kg & & & \\
$\quad$ (median and range) & & & \\
\hline
\end{tabular}

MVR, Mitral valve replacement.

complications include morbidity associated with long-term anticoagulation, the need for subsequent prosthetic valve replacement as the child outgrows the initial valve, and an ongoing risk of endocarditis and arrhythmias. ${ }^{2,7-9}$ The purpose of this study was to use competing-risks methodology to examine time-related risk factors associated with the mutually exclusive events of death and repeat replacement in children after MVR.

\section{Patients and Methods \\ Study Subjects}

Patients with MVR performed between January 1980 and February 2003 were identified from computerized databases. Some patients who were included had prior MVR, and these prior MVR episodes were included in the study, some of which dated back to January 1973.

\section{Data Collection and Measurements}

The study was approved by the institutional research ethics board. Data collected from medical record review included patient demographics, preoperative cardiac and noncardiac diagnoses, clinical condition, previous procedures and complications, echocardiographic and cardiac catheterization assessments and procedures, operative data, and postoperative and follow-up clinical status, including echocardiographic measurements.

\section{Data Analysis}

Data are described as frequencies, medians with ranges, and means with SDs. Where data are missing, the number of nonmissing values is given. Both replaced valve failure with subsequent replacement and mortality were modeled as time-dependent events by using both Kaplan-Meier estimates and parametric methods, with the association with risk factors being explored in multivariable analysis with bootstrap bagging. ${ }^{10}$ Competing-risks analysis was used in a manner previously reported. ${ }^{11}$ Post-MVR echocardiographic assessments of mean diastolic valve gradient and estimated right ventricular systolic pressure were modeled, and risk factors were sought by using mixed linear regression.

\section{Results}

\section{Patient Characteristics}

During the study period, 104 patients (52 male patients) underwent an initial MVR. The underlying valve disease was congenital in 86 patients, rheumatic in 14 patients (including 1 patient with endocarditis), Marfan syndrome in 3 patients, and isolated endocarditis in 1 patient. Congenital heart disease in 86 patients included atrioventricular septal defect (AVSD) in 31 patients, multiple left-sided obstructive lesions in 17 patients, atrioventricular discordance with Ebstein malformation in 16 patients, other cardiac lesions in 8 patients, and isolated mitral valve (MV) anomaly in 14 patients. Left-sided lesions included aortic coarctation in 11 patients, aortic valve stenosis or regurgitation in 29 patients, and subaortic obstruction in 16 patients. Before MVR, procedures to address other cardiac lesions were performed in 60 patients. Associated syndromes in 17 patients included Down syndrome in 9 patients, Marfan syndrome in 3 patients, Scheie syndrome in 2 patients, and William, Kartagener, and Treacher-Collins syndromes in 1 patient each. The MV dysfunction was primarily regurgitation in 67 patients, stenosis in 17 patients, and both in 20 patients. Other than repair of the AVSD, previous MV procedures had been performed in 33 patients, followed by a second procedure in 4 patients. Procedures included valvuloplasty in 22 patients, valvotomy in 8 patients, and repair in 14 patients.

\section{MVR}

Of the 104 patients, during the study interval, 78 patients had only 1 MVR (18 subsequently died), 20 patients had 2 MVRs ( 9 subsequently died), 5 patients had 3 MVRs, and 1 patient had 4 MVRs (all currently surviving) for a total of 137 MVR episodes. The characteristics at the MVR episode are shown in Table 1. The distribution of ages at the initial MVR was bimodal, with an early peak around the 25th percentile of 1.4 years and a later smaller peak around the 75th percentile of 12.3 years. The age at initial MVR was significantly younger in those with congenital heart disease versus those with other pathologic conditions $(P=.004)$, although those with congenital heart disease predominated throughout all ages. Total mortality for all patients regardless of subsequent procedures is shown in Figure 1. The 


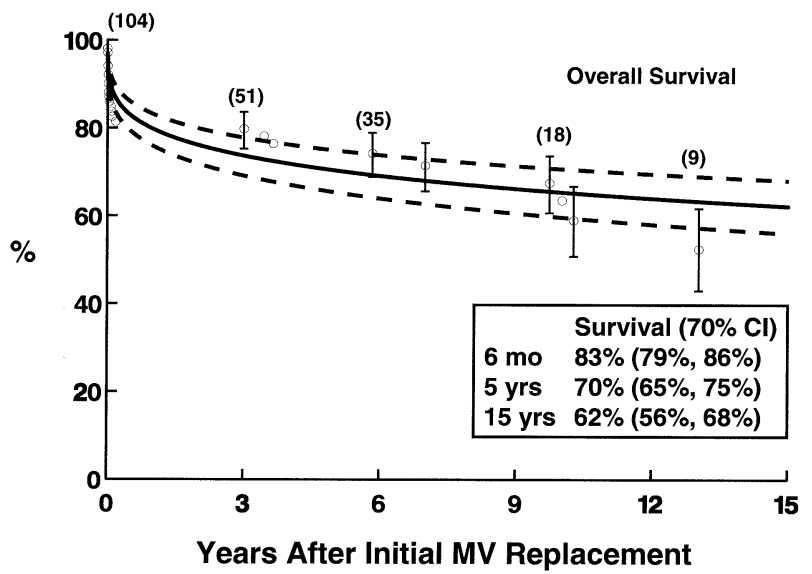

Figure 1. Overall time-related survival. All patients began at the time of initial MVR $(n=104)$ and are censored at the time of the last follow-up assessment. Solid lines represent parametric point estimates, dashed lines enclose $70 \%$ confidence intervals, circles with error bars represent nonparametric estimates, and numbers in parentheses represent the number of patients at risk.

analysis of early and late complications relates to the total 137 episodes of MVR.

\section{Postoperative Clinical Course}

There were 17 deaths within 30 days of MVR. Postoperative complications included reoperation for bleeding in $13(9 \%)$ MVRs, severe sepsis in $8(6 \%)$ MVRs, and arrhythmias requiring medical therapy in 34 (25\%) MVRs. Temporary pacing was required for $4(3 \%)$ MVRs, and permanent pacemaker placement was required for 14 (10\%) MVRs. A paravalvular leak was present in $7(5 \%)$ MVRs, with a stroke occurring in $5(3 \%)$ MVRs. A reoperation before hospital discharge was performed after 26 (19\%) MVRs, including revision in $4 \mathrm{MVRs}$ or replacement of the prosthesis in 3 MVRs.

\section{Late Complications}

There was also important late morbidity after the 117 MVRs not complicated by death or subsequent MVR within 30 days of MVR. There was an episode of important bleeding related to anticoagulation with $6(5 \%)$ MVRs, with 2 episodes of embolism caused by thrombus and 3 with transient ischemic attacks. There were an additional $6(5 \%)$ permanent pacemaker implantations. Late arrhythmias occurred with 16 (14\%) MVRs. There were $6(5 \%)$ later episodes of endocarditis, 3 (3\%) of valve thrombosis, and 17 (15\%) of perivalvular leak. Anticoagulation at latest follow-up assessment included warfarin in 86 MVRs, aspirin in 15 MVRs, persantin in 9 MVRs, and no anticoagulation in 7 MVRs. Only one patient with underlying congenital heart disease had cardiac transplantation at 9 years after a second MVR.

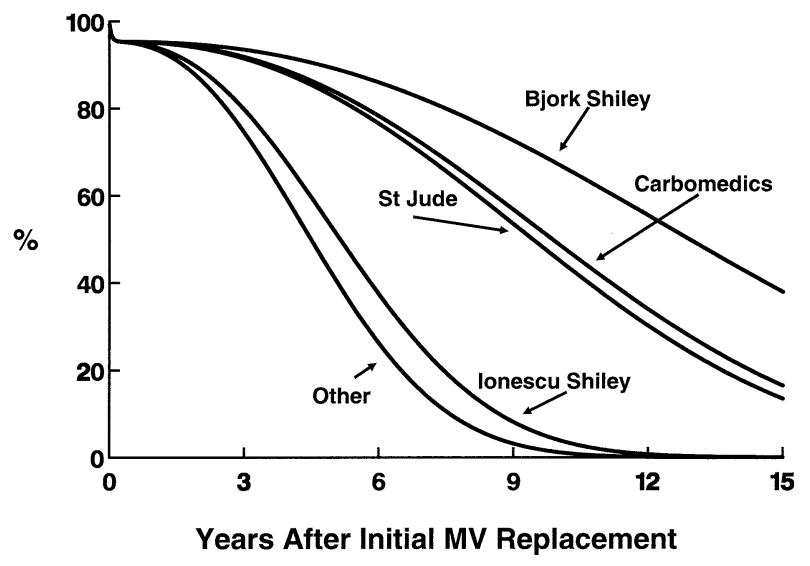

Figure 2. Time-related survival to subsequent replacement of the initial valve prosthesis stratified by initial prosthesis type. All patients began at the time of initial MVR $(n=104)$. Lines represent parametric point estimates.

Competing Risks for Death or Subsequent Prosthesis Replacement After Initial MVR

The competing-risks analysis relates outcomes only after the initial MVR for each of the 104 patients. During follow-up of the 104 initial MVR episodes, 26 valves were subsequently replaced, and 18 patients died without a further MVR. The hazard function for time-related transition to a second MVR was characterized by a very brief and steep early hazard phase (4 early-phase events) and a prolonged late hazard phase (22 late-phase events). The hazard function for time-related transition to death without a second MVR was characterized by a very steep early hazard phase only. The competing risks for the 2 events showed that after 15 years from initial MVR, $71 \%$ of valves had been replaced, $19 \%$ of patients had died without a further MVR, and $10 \%$ were surviving without a further MVR (Figure 2). Incremental risk factors each for early-phase death and for late-phase subsequent replacement after initial MVR were sought and are shown in Table 2. A stratified graph of valve longevity by different types of initial prosthesis shows that mechanical valves (St Jude Medical [St Jude Medical, Inc, St Paul, Minn], Björk-Shiley [Shiley, Inc, Irvine, Calif], and Carbomedics [Sulzer Carbomedics, Inc, Austin, Tex)] had similar and better longevity than tissue valves (IonescuShiley [Shiley] and other tissue valves, Figure 3). From the multivariable competing-risks analysis, predicted outcomes for a patient with good characteristics, including weight at initial MVR of $20 \mathrm{~kg}$, underlying AVSD after repair, and a cardiopulmonary bypass (CPB) time of 120 minutes with placement of a mechanical valve prosthesis, would show a $6 \%$ chance of death with a second MVR, a $74 \%$ chance of a second MVR, and a $20 \%$ chance of survival with the original prosthesis in place 15 years later. In contrast, for a 
TABLE 2. Incremental risk factors for time-related transition from initial MVR $(n=104)$ to either death or a second MVR

\begin{tabular}{|c|c|c|c|}
\hline & Parameter estimate $( \pm \mathrm{SE})$ & $P$ value & Reliability (\%) \\
\hline \multicolumn{4}{|l|}{ 1. For death without subsequent MVR* } \\
\hline Lower patient weight at MVR $(\mathrm{kg}) \dagger$ & $9.93 \pm 2.78$ & $<.001$ & 89 \\
\hline Initial valve morphology other than congenital heart disease & $1.31 \pm 0.64$ & .04 & 51 \\
\hline Longer duration of cardiopulmonary bypass at MVR (min)‡ & $0.000016 \pm 0.000004$ & $<.001$ & 47 \\
\hline \multicolumn{4}{|l|}{ 2. For survival to a subsequent MVR§ } \\
\hline Presence of multiple left-heart obstructive anomalies & $2.57 \pm 0.53$ & $<.001$ & 81 \\
\hline Ionescu-Shiley valve type & $1.42 \pm 0.56$ & .02 & 60 \\
\hline
\end{tabular}

*Final multivariable model included a significant missing value marker variable for weight.

†After inverse transformation.

$\ddagger$ After squared transformation.

§Risk factors were sought only for late-phase events because there were too few early-phase events.

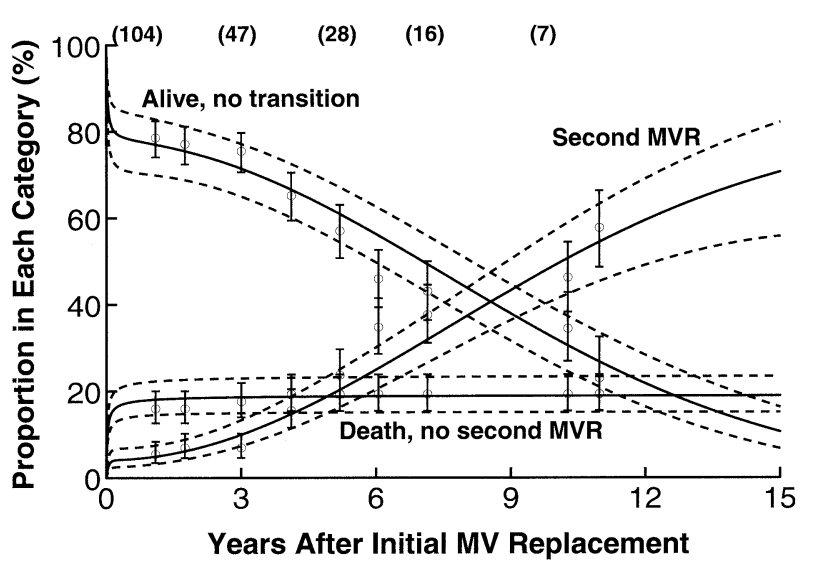

Figure 3. Competing-risks analysis for subsequent replacement of the initial replaced mitral valve or death. All patients began at the time of initial MVR $(n=104)$ and could transition to either death or a subsequent replacement. Solid lines represent parametric point estimates, dashed lines enclose $70 \%$ confidence intervals, and circles with error bars represent nonparametric estimates. The proportion of patients (expressed as percentage of total) in each of 3 categories at any given time after initial MVR is shown. Numbers in parentheses represent the number of patients at risk.

patient weighing $5 \mathrm{~kg}$ with underlying multiple left-heart obstructive lesions who undergoes placement of an IonescuShiley valve prosthesis with a prolonged CPB time of 480 minutes, predicted outcomes 15 years later would show a $96 \%$ chance of death without a second MVR and a $4 \%$ chance of a second MVR with almost no chance of survival with the original prosthesis in place.

A competing-risks analysis was performed for outcomes for the 26 patients who had a second MVR. The hazard function for time-related transition to another subsequent MVR for 6 patients was characterized by a constant hazard phase. The hazard function for timerelated transition to death without a further MVR for 9 patients was characterized by a prolonged early hazard phase. The competing risks for the 2 events showed that after 10 years from the second MVR, 37\% of valves had been replaced, $42 \%$ of patients had died without further MVR, and $21 \%$ of patients were surviving without further MVR. For comparison, at 10 years after the initial MVR, $49 \%$ of valves had been replaced, $19 \%$ of patients had died, and $32 \%$ of patients were surviving without a second MVR.

Factors Associated with Serial Echocardiographic Measurements After MVR

Mean echocardiographic gradient across the replaced MV was available after 54 MVRs, with a total of 256 measurements performed up to a maximum interval of 11.7 years (mean, 3.2 years). Significant independent factors associated with a higher mean gradient during follow-up included an increased interval from MVR (increase of $0.76 \mathrm{~mm} \mathrm{Hg}$ per year; $P<.001$ ) and a smaller absolute size of the MV implanted (increase of $0.40 \mathrm{~mm} \mathrm{Hg}$ per $1 \mathrm{~mm}$ decrease in diameter; $P<.001$ ). After controlling for these 2 factors, no other factor was significantly associated with follow-up gradient, including the age and size of the patient, the cardiac morphology, or the type of prosthesis that was implanted.

Estimated right ventricular systolic pressure was available after 41 MVRs, with a total of 157 measurements performed up to a maximum interval of 11.7 years (mean, 3.0 years). The only significant independent factor associated with a higher right ventricular systolic pressure during follow-up was an increased interval from MVR (increase of $1.03 \mathrm{~mm} \mathrm{Hg}$ per year; $P=.002$ ).

\section{Discussion}

This study reports a single institutional experience with MVR in 104 pediatric patients. The results of the competing-risk analysis provide valuable information regarding the timerelated risk of death without repeat replacement and valve longevity. 


\section{Mortality}

Similar to our study, reported mortality in young children with MV disease has been high, particularly for patients undergoing MVR, with most of the deaths occurring early. Kadoba and colleagues ${ }^{5}$ reported a $36 \%$ likelihood of death in the first year of life and a 20\% likelihood of late death. Hospital mortality has significantly decreased in recent years, ranging from $12 \%$ to $33 \%$. ${ }^{1}$ High mortality has been associated with a greater ratio of prosthetic valve size to body weight. Ultimately, even the smallest available prosthetic valves are considered too large for placement in small patients, resulting in higher mortality. ${ }^{2,3}$ Additional surgical options for small patients include further attempts at valve repair, abandonment of the left ventricle, and performance of an atrial septectomy and Damus-Kaye-Stanzel-type anastomosis or transplantation. ${ }^{12}$

We noted that initial valve morphology other than congenital heart disease was a risk for mortality. This group included 14 patients with rheumatic heart disease (1 died), 1 with endocarditis (who died), and 3 with Marfan syndrome (2 died). The benefits of reconstructive surgery are important for young patients with Marfan syndrome, who usually have a higher risk of aortic dissection. ${ }^{13}$ Recent reports suggest that MV reconstruction in the setting of active or healed endocarditis is feasible, can be performed with low operative mortality and morbidity, and should be considered rather than MVR for mitral regurgitation caused by endocarditis. ${ }^{14}$ A 15 -year study of rheumatic heart disease showed that the mean age at hospitalization was $11 \pm$ 3 years. ${ }^{15}$ In our study, data suggest that older and younger patients might have different underlying diagnoses, with higher-risk noncongenital valve disease more likely in adolescents.

Longer duration of $\mathrm{CPB}$ was also identified as a risk factor for death without a repeat MVR. Bypass time might be acting as a proxy for disease complexity. All organ systems could be adversely affected by CPB, primarily the heart, lungs, brain, and kidneys. The risk of serious complications depends on the age of the patient, how ill they are at the time of the operation, and the complexity of the operation to be performed. The mean CPB time for the entire cohort was $154 \pm 75$ minutes compared with $317 \pm$ 113 minutes for patients who died without repeat MVR. In 8 of the 10 MVRs with the longest duration of bypass, there were other operations being performed concomitantly, including aortic valve replacement or reconstruction with the Ross or Konno procedure, repair of the AVSD, bidirectional cavopulmonary anastomosis, and Fontan procedure.

\section{Prosthetic Valve Longevity}

We identified 2 risk factors for decreased time to a repeat MVR after initial MVR: (1) the presence of multiple leftheart obstructive anomalies and (2) Ionescu-Shiley valve type. Left-heart lesions included aortic coarctation, aortic valve stenosis or regurgitation, and subaortic obstruction. The presence of other left-heart anomalies might place an added burden on the prosthetic valve, particularly if there is associated aortic stenosis.

The choice of prosthetic valve type is still debated. In our study the majority of patients (37\%) underwent MVR with a St Jude Medical prosthetic valve. The advantages of a mechanical prosthesis include better hemodynamic flow characteristics for valves that are small in size, with a lower profile associated with less potential for left ventricular outflow tract obstruction and longer durability. ${ }^{1,6,16}$ Anticoagulation regimen remains a matter of concern for patients with mechanical valves. We noted that $10 \%$ of patients received Ionescu-Shiley valves, which was characterized as a risk factor for reduced valve longevity. Zweng and associates $^{6}$ report that 4 of 10 patients with a bioprosthesis underwent reoperation within 17 to 47 months of an initial MVR. Although bioprosthetic valves do not require anticoagulation, they do have problems of limited durability. ${ }^{1,4}$

The results of this study show that the need for multiple MVR might increase mortality. The most significant increase in mortality was seen after 2 operations. Of the 20 patients who had 2 MVRs, 9 died without a third MVR. Five patients had 3 MVRs with no deaths, and 1 patient is a current survivor after 4 MVRs. We also noted that patients who required a subsequent MVR within 4 months of the initial MVR had higher mortality. In addition, patients aged less than 1 year at the time of their initial MVR were at high risk for both early death and an early subsequent MVR (with associated high mortality).

Late complications were common. Prosthetic valve thrombosis and embolism are comparatively frequent complications after valve replacement operations. ${ }^{7,17,18}$ Previous studies have reported rates of thromboembolism of $0.7 \%$ to $2 \%$ per year. ${ }^{1,4}$ Bacterial endocarditis and bleeding after MVR were reported in previous studies. $5,7,9,19,20$

Echocardiography remains the mainstay of follow-up assessment. We noted that significant independent factors associated with higher mean echocardiographic diastolic gradient during follow-up included an increasing interval from MVR (gradient worsens in a linear manner with time) and a smaller absolute size of the prosthesis implanted. Matsuoka and coworkers ${ }^{21}$ noted that 3 children with MVRs with a St Jude Medical prosthesis of $23 \mathrm{~mm}$ or smaller had greater mean echocardiographic diastolic gradients than those who received prostheses of $25 \mathrm{~mm}$ or larger. We also noted that the only significant factor associated with higher right ventricular systolic pressure during follow-up was an increased interval from MVR (pressure increases with time). 


\section{Summary}

The results of our study show that lower patient weight, valve morphology other than congenital heart disease, and longer duration of CPB at initial MVR are significant predictors of death without a repeat MVR. Furthermore, the presence of multiple left-heart obstructive anomalies and use of the Ionescu-Shiley or bioprosthetic valve types were identified as significant risk factors for earlier repeat MVR. Ultimately, valve replacement might be necessary in children with extremely dysplastic valves and severe hemodynamic impairment or after failed repair. However, with the appropriate selection of the prosthetic valve and reduction of CPB time, surgeons might decrease morbidity and mortality in pediatric patients undergoing MVR.

\section{References}

1. Gunther T, Mazzitelli D, Schreiber C, Wottke M, Paek SU, Meisner H, et al. Mitral-valve replacement in children under 6 years of age. Eur J Cardiothorac Surg. 2000;17:426-30.

2. Erez E, Kanter KR, Isom E, Williams WH, Tam VK. Mitral valve replacement in children. $J$ Heart Valve Dis. 2003;12:25-9.

3. Raghuveer G, Caldarone CA, Hills CB, Atkins DL, Belmont JM, Moller $\mathrm{JH}$. Predictors of prosthesis survival, growth, and functional status following mechanical mitral valve replacement in children aged $<5$ years, a multi-institutional study. Circulation. 2003;108(suppl 1):II174-9.

4. Alexiou C, Galogavrou M, Chen Q, McDonald A, Salmon AP, Keeton BK, et al. Mitral valve replacement with mechanical prostheses in children: improved operative risk and survival. Eur J Cardiothorac Surg. 2001;20:105-13.

5. Kadoba K, Jonas RA, Mayer JE, Castaneda AR. Mitral valve replacement in the first year of life. J Thorac Cardiovasc Surg. 1990;100: $762-8$.

6. Zweng TN, Bluett MK, Mosca R, Callow LB, Bove EL. Mitral valve replacement in the first 5 years of life. Ann Thorac Surg. 1989;47: 720-4.

7. el Makhlouf A, Friedli B, Oberhansli I, Rouge JC, Faidutti B. Prosthetic heart valve replacement in children. Results and follow-up of 273 patients. J Thorac Cardiovasc Surg. 1987;93:80-5.

8. Robbins RC, Bowman FO Jr, Malm JR. Cardiac valve replacement in children: a twenty-year series. Ann Thorac Surg. 1988;45:56-61.

9. Yoshimura N, Yamaguchi M, Oshima Y, Oka S, Ootaki Y, Murakami $\mathrm{H}$, et al. Surgery for mitral valve disease in the pediatric age group. J Thorac Cardiovasc Surg. 1999;118:99-106.

10. Blackstone EH, Naftel DC, Turner ME Jr. The decomposition of time-varying hazard into phases, each incorporating a separate stream of concomitant information. J Am Stat Assoc. 1986;81:615-24.

11. McGiffin DC, Naftel DC, Kirklin JK, Morrow WR, Towbin J, Shaddy $\mathrm{R}$, et al. Predicting outcome after listing for heart transplantation in children: comparison of Kaplan-Meier and parametric competing risk analysis. Pediatric Heart Transplant Study Group. J Heart Lung Transplant. 1997; 16:713-22.

12. Caldarone CA, Raghuveer G, Hills CB, Atkins DL, Burns TL, Behrendt DM, et al. Long-term survival after mitral valve replacement in children aged $<5$ years: a multi-institutional study. Circulation. 2001;104(suppl 1):I143-7.

13. Fuzellier JF, Chauvaud SM, Fornes P, Berrebi AJ, Lajos PS, Bruneval $P$, et al. Surgical management of mitral regurgitation associated with Marfan's syndrome. Ann Thorac Surg. 1998;66:68-72.

14. Pagani FD, Monaghan HL, Deeb GM, Bolling SF. Mitral valve reconstruction for active and healed endocarditis. Circulation. 1996; 94(suppl):II133-8.

15. Bitar FF, Hayek P, Obeid M, Gharzeddine W, Mikati M, Dbaibo GS. Rheumatic fever in children: a 15-year experience in a developing country. Pediatr Cardiol. 2000;21:119-22.
16. Pass HI, Sade RM, Crawford FA, Hohn AR. Cardiac valve prostheses in children without anticoagulation. J Thorac Cardiovasc Surg. 1984; 87:832-5.

17. Bradley SM, Sade RM, Crawford FA Jr, Stroud MR. Anticoagulation in children with mechanical valve prostheses. Ann Thorac Surg. 1997; 64:30-4.

18. Harada Y, Imai Y, Kurosawa H, Ishihara K, Kawada M, Fukuchi S. Ten-year follow-up after valve replacement with the St. Jude Medical prosthesis in children. J Thorac Cardiovasc Surg. 1990;100:175-80.

19. Williams WG, Pollock JC, Geiss DM, Trusler GA, Fowler RS. Experience with aortic and mitral valve replacement in children. $J$ Thorac Cardiovasc Surg. 1981;81:326-33.

20. Abid F, Abid A, Fekih M, Zaouali RM, Ben Ismail M. Aortic valve replacement in children under 16 years of age with congenital or rheumatic valvular disease. A study of 64 cases. J Cardiovasc Surg (Torino). 1992;33:265-71.

21. Matsuoka Y, Nishiguchi T, Nakachi T, Hayakawa K, Onitsuka T, Koga Y. Continuous wave Doppler echocardiographic evaluation of St. Jude prosthetic mitral valves in children. Acta Paediatr Jpn. 1990; 32:663-9.

\section{Discussion}

Dr Vincent Tam (Fort Worth, Tex). MVR in children is a difficult subject to study because even in a large-volume center such as yours, few patients undergo MVR each year. In addition to the small number of patients, there is a great variability in the underlying MV disease and associated cardiac disease; the patients' ages and sizes span the entire spectrum from newborn to young adults.

Your results demonstrate some expected findings but also some unexpected findings as well. I have a few questions.

Your study encompassed a 23-year period. Have you analyzed results, looked for any period differences, for example, comparing the last decade with the previous 13 years?

Can you explain why the underlying valve pathology, other than congenital, was identified as an incremental risk factor for death, particularly because these seem to occur mostly in the older and larger patients?

Why is the mortality after the second MVR higher despite potentially larger patient size? Were there a number of second MVRs during the same hospitalization as the initial MVR? In conjunction with this question, why is the hazard function for death without repeat MVR different for the initial MVR versus a second MVR?

Given the model that you have, what would you recommend for a 4-kg child with infantile Marfan syndrome and severe MV regurgitation, which I did not repair very well 2 days ago? What should I do?

Last, is there any role for a bioprosthetic MVR in the pediatric population? What would the longevity and mortality be for a bioprosthetic MVR in an 18-year-old woman?

I commend the authors for their efforts in studying this difficult subject.

Dr Caldarone. Thank you for your kind comments. We agree that the question of an era effect is appropriate. The year of operation was entered into the analysis and did not come out as a significant risk factor; however, that does not mean an era effect is absent. As you pointed out, a small series looking at a diverse population requires analysis of a large number of variables, and therefore a small effect in any one variable might not be detected. I would suspect there is an era effect, but we were unable to detect one. 
With regard to the identification of noncongenital diagnosis as a risk factor for death, I share with you some concern with the use of a basket term encompassing a diverse group of diagnoses, especially a negative basket term meaning all diagnoses of noncongenital origin. This technique lumps together these diagnoses, and in aggregate they became statistically significant, when in isolation they did not. Once again, this underscores the problem with a large number of variables and a small data set.

The noncongenital deaths were basically related to rheumatic disease, endocarditis, Marfan syndrome, and Shone syndrome. In fact, 3 of the deaths were quite late deaths at 4, 4, and 10 years after the operation, respectively. Therefore, in terms of decision making in a patient with noncongenital MV disease, I really do not think that should necessarily sway your decision about whether to implant a valve.

With regard to the deaths after a second MVR, you have very nicely pointed out one of the problems with our analysis. Patients who had a short interval from the first to the second MVR and then subsequently died after the second MVR were not identified in the analysis looking at the first MVR. These were censored events because they recurred after a second MVR. That might be an inappropriate way to deal with this statistically because a patient who requires 2 MVRs in the same hospital admission clearly is not the same as a patient showing up electively for a second MVR years later. Therefore, your point in that respect is well taken.

With regard to the poor-risk patient you described, there is no easy answer. Repair, repair, and replace when necessary is what we all use as our decision making, and it seems appropriate in the patient you described. I think attempts at persistent replacement need to be tempered with the fact that a patient with poor physiologic status as a result of multiple futile attempts at repair might be worse off than just biting the bullet up front and replacing the valve. Therefore, in short, I would say the patient should have one trip to the operating room for attempted repair. If the patient subsequently requires a return to the operating room, I would advocate another attempt at repair, and if it does not look satisfactory in the operating room, the valve should be replaced.

Finally, what is the ideal patient for a tissue prosthesis? As patients get older, I suspect the tissue prostheses will last longer.
We could run our model and see if that actually is true. Ideally, in a female patient you would want to skip the childbearing age with a bioprosthesis in place, and after childbearing age, you would want to be able to have a mechanical prosthesis for the rest of her life. Therefore, I would say that would be the ideal indication.

Dr Gerhard Ziemer (Tuebingen, Germany). I have 2 questions. Did you ever encounter any secondary tricuspid valve problems by distortion when you had to use valves in the 4 to $6 \mathrm{~mm} / \mathrm{kg}$ range, such as in neonates or young infants?

Also, do you have any clue why the Carbomedics valve turned out to be better in your risk analysis? Has it something to do with the design?

Dr Caldarone. Personally, I have not run into distortion of the tricuspid valve from the MV prosthesis; however, I have run into patients with pulmonary hypertension, which causes tricuspid insufficiency and might require tricuspid repair at the time of MVR.

With regard to the Carbomedics valve, there were no statistically significant differences between the mechanical valve types. Although on the survival curve it looked like there were differences, the differences were not statistically significant.

Dr Carlo Marcelletti (Palermo, Italy). I would like to ask about the incidence of complete atrioventricular block in MVR in the setting of partial or complete AVSD.

Dr Caldarone. It was $10 \%$ in the entire series and $15 \%$ in patients with AVSDs.

Dr C. Troconis (Caracas, Venezuela). Is there any role for an autologous tricuspid valve translocation from the tricuspid site for the MVR and implanting a cryopreserved bioprosthetic valve in the right side in the pediatric population?

Dr Caldarone. No, that was not done in this series.

Dr Ross M. Ungerleider (Portland, Ore). I assume that $5 \mathrm{~kg}$ was the smallest patient in your series, and yet sometimes we see patients who are smaller. Is there any role for the Ross II operation, maybe with an aortic homograft and a small polytetrafluoroethylene tube? Have you tried any novel approaches like that?

Dr Caldarone. Personally, I have not. There were either 2 or 3 homograft replacements in the series, but because there were so few, we could not really identify that as a risk factor or benefit.

\section{Availability of Journal back issues}

As a service to our subscribers, copies of back issues of The Journal of Thoracic and Cardiovascular Surgery for the preceding 5 years are maintained and are available for purchase from Elsevier Inc. until inventory is depleted. Please write to Elsevier Inc., Subscription Customer Service, 6277 Sea Harbor Dr, Orlando, FL 32877 , or call $800-654-2452$ or $407-345-4000$ for information on availability of particular issues and prices. 